\title{
Comparison of full-field electroretinogram in diabetic and non diabetic dogs with cataracts ${ }^{1}$
}

\author{
Angélica M.V. Safatle ${ }^{2^{*}}$, Ana Paula Hvenegaard ${ }^{2}$, Denise Otsuki ${ }^{3}$, Terezinha L. \\ Martins $^{3}$, Márcia Kahvegian ${ }^{3}$, Adriana Berezovsky ${ }^{4}$, Solange R. Salomão ${ }^{4}$ \\ and Paulo S.M. Barros ${ }^{2}$
}

\begin{abstract}
Safatle A.M.V., Hvenegaard A.P., Otsuki D., Martins T.L., Kahvegian M., Berezovsky A., Salomão S.R. \& Barros P.S.M. 2010. Comparison of full-field electroretinogram in diabetic and non diabetic dogs with cataracts. Pesquisa Veterinária Brasileira 30(12):1071-1076. Laboratory of Investigation in Comparative Ophthalmology, Veterinary Teaching Hospital, School of Veterinary Medicine, University of São Paulo, Av. Prof. Dr. Orlando de Marques de Paiva 87, Bloco 8 superior, Cidade Universitária, São Paulo, SP 05508-270, Brazil. E-mail: angsaf@usp.br

Being the commonest ocular disorder, dense cataracts disable fundoscopic examination and the diagnosis of retinal disorders, which dogs may be predisposed. The aim of this study was to compare the electroretinographic responses recorded according to the International Society for Clinical Electrophysiology of Vision human protocol to evaluate retinal function of diabetic and non diabetic dogs, both presenting mature or hypermature cataracts. Full-field electroretinogram was recorded from 66 dogs, with ages varying from 6 to 15 years old allocated into two groups: (1) CG, non diabetic cataractous dogs, and (2) DG, diabetic cataractous dogs. Mean peak-to-peak amplitude (microvolts) and b-wave implicit time (milliseconds) were determined for each of the five standard full-field ERG responses (rod response, maximal response, oscillatory potentials, single-flash cone response and 30 $\mathrm{Hz}$ flicker). Comparing CG to DG, ERGs recorded from diabetic dogs presented lower amplitude and prolonged $b$-wave implicit time in all ERG responses. Prolonged $b$-wave implicit time was statistically significant ( $p<0.05)$ at $30 \mathrm{~Hz}$ flicker $(24.0 \mathrm{~ms}$ versus $22.4 \mathrm{~ms}$ ). These data suggests full-field ERG is capable to record sensible alterations, such as flicker's implicit time, being useful to investigate retinal dysfunction in diabetic dogs.
\end{abstract}

INDEX TERMS: Electroretinogram, dogs, cataracts, diabetes mellitus, diabetic retinopathy, retina.

RESUMO.- [Estudo comparativo do eletrorretinograma de campo total em cães diabéticos e não diabéticos com catarata.] Catarata madura e hipermadura, alteração frequentemente observada em cães, impossibilita a visibilização do fundo do olho e provável diagnóstico de degenerações

\footnotetext{
${ }^{1}$ Received on March 26, 2010.

Accepted for publication on September 5, 2010.

2 Laboratório de Investigação em Oftalmologia Comparada, Departamento de Cirurgia, Faculdade de Medicina Veterinária e Zootecnia, Universidade de São Paulo (USP), Av. Prof. Dr. Orlando Marques de Paiva 87, Cidade Universitária, São Paulo, SP 05508 270, Brazil. ${ }^{\star}$ Corresponding author: angsaf@usp.br

${ }^{3}$ Faculdade de Medicina, USP, Av. Dr. Enéas de Carvalho Aguiar 255, Cerqueira César, São Paulo, SP 05403-000.

${ }^{4}$ Escola Paulista de Medicina, Universidade Federal de São Paulo (Unifesp), Rua Botucatu 740, São Paulo, SP 04023-900.
}

retinianas. Objetivou-se comparar as respostas retiniana de cães diabéticos e não diabéticos, ambos portadores de catarata madura ou hipermadura, com auxílio do eletrorretinograma de campo total, utilizando o protocolo da International Society for Clinical Electrophysiology of Vision. Sessenta e seis cães, com idades variando entre 6 a 15 anos de idade foram divididos em dois grupos: (1) CG, cães não diabéticos com catarata madura ou hipermadura e (2) DG, cães diabéticos com catarata madura ou hipermadura. Mensurouse amplitude pico a pico (microvolts) e tempo de culminação da onda-b (milisegundos) para as cinco respostas do ERG (resposta de bastonetes, máxima resposta, potencial oscilatório, resposta de cones e flicker a $30 \mathrm{~Hz}$ ). Avaliandose as respostas obtidas com o exame, o grupo de cães diabéticos apresentou menor amplitude e maior tempo de culminação da onda-b em todas as respostas. $\mathrm{O}$ aumento 
do tempo de culminação da onda-b em DG foi estatisticamente significante $(p<0.05)$ no flicker a $30 \mathrm{~Hz}(24.0 \mathrm{~ms}$ versus $22.4 \mathrm{~ms}$ ). ERG de campo total é capaz de registrar alterações em respostas sensíveis como o tempo de culminação da onda-b do flicker, podendo ser útil para investigar retinopatias em cães diabéticos.

TERMOS DE INDEXAÇÃO: Eletrorretinograma, cão, catarata, diabetes mellitus, retinopatia diabética, retina.

\section{INTRODUCTION}

Diabetes mellitus (DM) is one of the most frequent disorders of endocrine pancreas in dogs and cats. The most common forms of diabetes vary with the species. In dogs, the commonest is Type 1, characterized by pancreatic â-cell destruction, which leads to absolute insulin deficiency (insulin-dependent diabetes mellitus) (Rand et al. 2004).

DM induces several ophthalmic disorders, being cataracts of acute onset, rapidly progressive and bilaterally symmetrical, the commonest ocular manifestation resulting blindness (Cullen \& Webb 2007, Ofri 2008). Lens-induced uveitis (LIU), lens capsule rupture, glaucoma and lens luxation may also be observed (Wilkie et al. 2006). Cataract extraction by phacoemulsification is the treatment of choice, recovering vision and preventing complications (Wilkie \& Colitz 2007). Prior to surgery, several tests can be required aiming to predict full visual restoration; one of these is the full-field electroretinogram (ERG) (Rubin 1971).

ERG is an objective electrodiagnostic method (Tzecov \& Arden 1999, Safatle et al. 2005) utilized to evaluate retinal function. Early detection of dysfunction at retinal external layers, even earlier than the appearance of clinical signs is commonly observed in this test (Komaromy et al. 1998). This exam has already shown itself of great importance in small animals, although it can also be used in large (Komaromy et al. 2003) and exotic animals (Hendrix \& Sims 2004). In dogs, ERG is mostly utilized for preoperative evaluation of patients presenting cataracts, for the characterization of disturbances causing blindness (Ekesten 2007) like glaucoma, achromatopsia (Rubin 1971, Hurn et al. 2003), retinal dysplasias, degenerative retinopathies (Safatle et al. 2005), optic nerve hypoplasia, sudden acquired retinal degeneration syndrome or neuronal ceroid lipofuscinoses (Narfström 2006), besides its use in dogs as animal models for scientific protocols (PetersenJones et al. 2006).

Nowadays, the most performed ERG protocol in animals was suggested by the European College of Veterinary Ophthalmology (ECVO) in 2002 and consists on 4 distinct responses (rod, maximal, cones and flicker response) (Narfström et al. 2002). In human medicine, an extra response is recorded: the oscillatory potential. This specific response originates from the interaction of the amacrine, ganglionic and bipolar cells (Nusinowitz \& Heckenlively 2006). Any reduction in this specific response may indicate retinal ischemia that is commonly observed in diabetic human patients with diabetic retinopathy (DR) (Kim et al. 1998). In
1989, the International Society for Clinical Electrophysiology of Vision (ISCEV) defined a human standard ERG protocol, in which those 5 recorded responses are obtained through a fully dilated pupil after thirty minutes of dark adaptation (Maehara et al. 2005).

The purpose of this study was to compare the full-field electroretinogram in diabetic and non diabetic dogs, both presenting mature or hypermature cataracts according to the ISCEV human standard ERG protocol.

\section{MATERIALS AND METHODS}

Dogs referred to the Veterinary Hospital of the School of Veterinary Medicine of the São Paulo University from 2006 to 2008 were included in this study according to the following criteria: diabetic and non diabetic dogs should present mature or hypermature cataracts, and no other systemic or ophthalmologic disorder.

Complete ophthalmological, clinical (including blood screen) and heart exams (electrocardiogram and arterial pressure measurement) were preformed in each subject. Ophthalmologic examinations included Schirmer tear test ${ }^{5}$, fluorescein stain ${ }^{6}$, applanation tonometry ${ }^{7}$, slit lamp biomicroscopy $^{8}$ and ocular ultrasound ${ }^{9}$.

After all the ophthalmic workup, sixty six dogs with ages varying from 6 to 15 years old (yo) were selected than, twenty nine were non diabetic dogs with cataracts (18 males and 11 females), and thirty seven were diabetic dogs ( 7 males and 30 females).

Studied breeds were: Mixed Breed dogs(23), Miniature Poodles(19), Brazilian Terriers(3), German Shepherds(3), Bichon Frisès (2), Malteses (2), Pinschers (2), Beagle(1), English Cocker Spaniel(1), Labrador Retriever(1), Lhasa Apso(1), Miniature Schnauzer(1), Pit Bull(1), Rottweiller(1), Sheepdog (1), Siberian Husky(1), Teckel(1), Weimaraner(1) and Yorkshire Terrier(1).

Animals were allocated in two groups: Cataract Group (CG) and Diabetic Group (DG) and were studied according to the Bioethics Committee of the institution, protocol n. 06/ 2001

Subjects' preparation for ERG. All subjects were fasted for at least 8 hours before ERG testing. Maximal pupillary dilation was obtained using one eye drop of $1 \%$ tropicamide ${ }^{10}$, followed by 1 drop of $10 \%$ phenylephrine hydrochloride ${ }^{11}$ at least 30 minutes prior to the ERG session.

Sedation protocol and dark adaptation. Dogs were premedicated with subcutaneous $0.044 \mathrm{mg} / \mathrm{kg}$ of atropine sulfate ${ }^{12}$. Eyes were dark adapted with occlusive bandage for 30 minutes. The sedation was performed with $0.5 \mathrm{mg} / \mathrm{kg}$ xylasine

\footnotetext{
5 Teste de Schirmer®, Ophthalmos Ind. Farmacêutica, São Paulo, SP, Brazil.

${ }^{6}$ Fluoresceína strips®, Ophthalmos Ind. Farmacêutica, São Paulo, SP, Brazil.

7 Tono-pen.XL, BIO-RAD, Hercules, CA, USA.

8 SL-14, Kowa Optimed Incorporation, Torrance, CA, USA.

${ }^{9}$ Accutome B-Scan Plus, Accutome Incorporation, Malvern, PA, USA.

${ }^{10}$ Mydriacyl 1\%®, Alcon Labs. do Brasil Ltda., São Paulo, SP, Brazil.

${ }^{11}$ Fenilefrina $10 \% ®$, Allergan Produtos farmacêuticos Ltda., São Paulo, SP, Brazil.

${ }^{12}$ Atropion $0.50 \mathrm{mg}{ }^{\circledR}$, Ariston, São Paulo, SP, Brazil.
} 
hydrochloride ${ }^{13}$ and $0.2 \mathrm{mg} / \mathrm{kg}$ butorphanol ${ }^{14}$. Subcutaneous 4 $\mathrm{mg} / \mathrm{kg}$ lydocaine ${ }^{15}$ was administered at the caudal lateral canthi of both eyelids to avoid palpebral movements.

ERG procedure. Electroretinograms were recorded from both eyes using the 2000 Veris System ${ }^{16}$.

A bipolar contact lens electrode ${ }^{17}$ was placed on both corneas after $2 \%$ methylcellulose eyedrops instillation ${ }^{18}$ to improve electrical contact and to protect ocular surfaces. Topical $0.5 \%$ proxymetacaine hydrochloride eyedrops ${ }^{19}$ was utilized to anesthetize both corneas. A ground electrode ${ }^{20}$ was filled with electrolytic gel and was placed at the earlobe, after its clipping and cleaning.

Patients were positioned in sternal recumbency while their whole heads were introduced inside the Ganzfeld stimulator. Third eyelid protrusion and bulb rotation were avoided and the eyes were kept centralized during the procedure.

ERG was simultaneously recorded from both eyes in a dark room, according to the ISCEV standard protocol, constituted of five responses: (1) a maximal intensity white light attenuated by a 2.4 log neutral density filter to elicit a dark-adapted rod response; (2) a maximal intensity white light to elicit a mixed dark-adapted rod and cone response; (3) the maximal intensity white light with a $100 \mathrm{~Hz}$ low-cut and $1 \mathrm{KHz}$ high-cut filter to elicit oscillatory potentials; - the maximal intensity white light on a $30 \mathrm{~cd} / \mathrm{m}^{2}$ background presented; (4) $1 \mathrm{~Hz}$; and (5) $30 \mathrm{~Hz}$ to elicit cone responses. A period of $10 \mathrm{~min}$ was allowed to adapt to the background light when collecting the cone responses.

\footnotetext{
${ }^{13}$ Xilazin $2 \% ®$, Syntec, Hortolândia, SP, Brazil.

14 Torbugesic 10 mg®, Fort Dodge, Campinas, SP, Brazil.

${ }^{15}$ Xylestesin 2\%®, Cristália, Itapira, SP, Brazil.

${ }^{16}$ ElectroDiagnostic Imaging Inc., San Mateo, USA.

${ }^{17}$ Burian Allen Electrode, Electro-Diagnostic Imaging, Inc., San Mateo, CA, USA.

${ }^{18}$ Metilcelulose $2 \%$, Ophthalmos Ind. Farmacêutica, São Paulo, SP, Brazil.

${ }^{19}$ Anestalcon $0.5 \% 囚$, Alcon Labs do Brasil Ltda, São Paulo, SP, Brazil.

20 Gold Disc Electrode in Ear Clip, Grass Instrument Division, Astro Med. Inc., West Warwick, RI, USA.
}

Twenty responses were computer-averaged for each step of the standard protocol, except for the $30 \mathrm{~Hz}$ flicker for which 50 responses were averaged.

After presenting standard dark- and light-adapted stimuli, each response was analyzed for a- and b-wave amplitude and implicit time. ERG parameters were measured from peak-topeak amplitudes differences: from the negative peak of the awave to the positive peak of the b-wave, in microvolts (iV); and implicit times, from the light onset to the positive peak of the bwave, in milliseconds (ms).

Full-field ERG testing sessions had as long as approximately 60 minutes, being the first thirty minutes spent for dark adaptation, and ten minutes for light adaptation.

Data analysis. For statistical analysis, only ERG recordings presenting little or none interference from one eye of each subject were chosen. Unpaired t test was performed to test the difference in means; when data failed Levene's test for equality of variances, a t test with Welch correction was performed.

Statistically significance differences were established at levels of $p<0.05$. SPSS software (version 16.0 for Windows, SPSS Inc.), was utilized to perform all statistical analysis.

\section{RESULTS}

All 5 standardized full-field ERG responses were successfully recorded in all subjects. Representative ERG waveforms obtained from 3 CG dogs and 3 DG dogs are shown in Figure 1 and 2 .

Overall, mean peak to peak amplitudes seemed to be smaller for each of the five standard protocol steps in DG when compared to $\mathrm{CG}$, but these findings had not reached statistical significance. $30 \mathrm{~Hz}$ flicker presented statistically prolonged $b$-wave implicit times $(p<0.05)$ in diabetic animals with cataracts when compared to CG (24.0ms versus 22.4ms).

Table 1 shows mean amplitudes (measured peak-to-peak from a-wave to b-wave) and respective standard deviations and implicit times for rod, maximal response, cone, flicker responses (average of sinusoidal peak-to-peak responses)

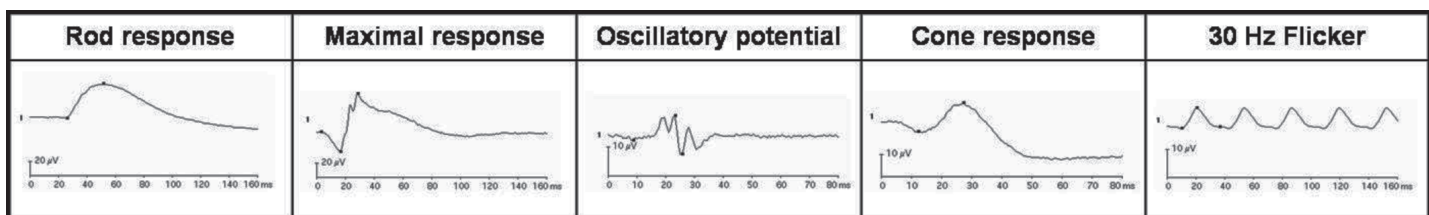

(a) Miniature Poodle, male, 7 years old, left eye with hypermature cataracts.

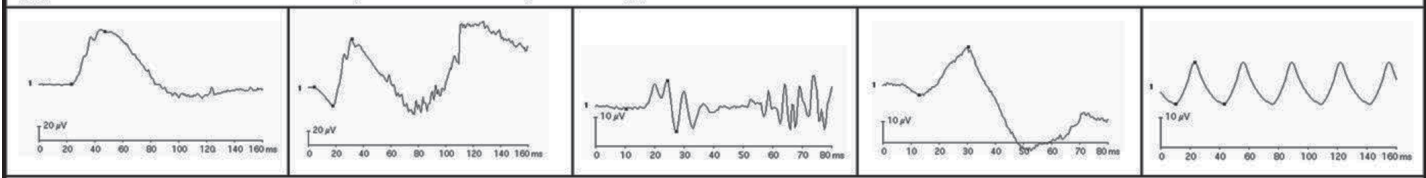

(b) Mixed breed, female, 7 years old, right eye with mature cataracts.

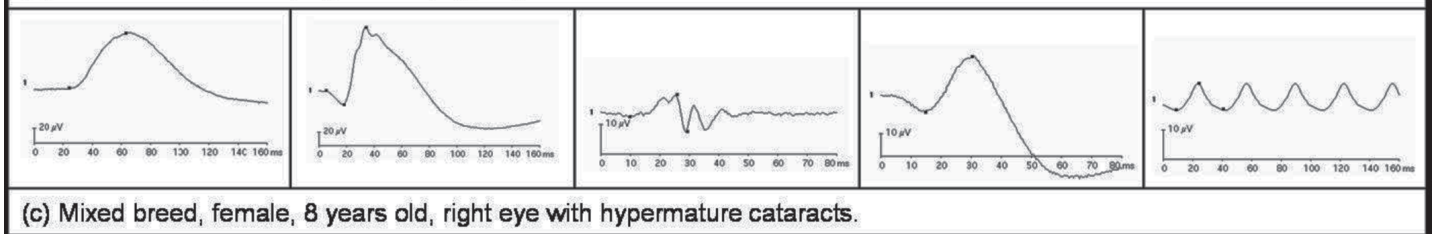

Fig.1. ERG waveforms obtained from three non diabetic dogs (a);(b);(c) with mature or hypermature cataracts according to ISCEV protocol. 


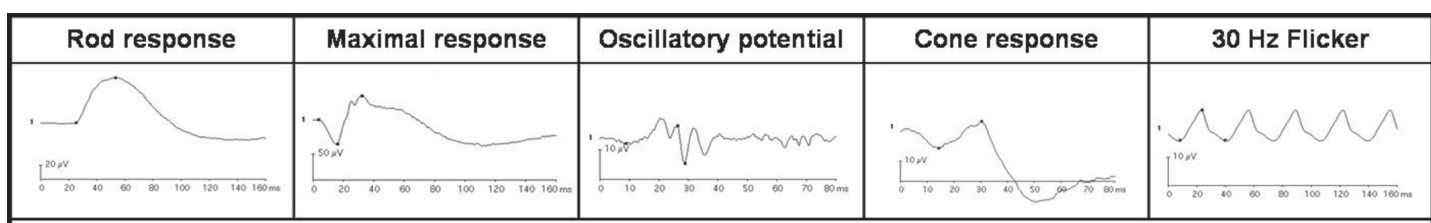

(d) Miniature Poodle, female, 13 years old, left eye with hypermature cataracts.

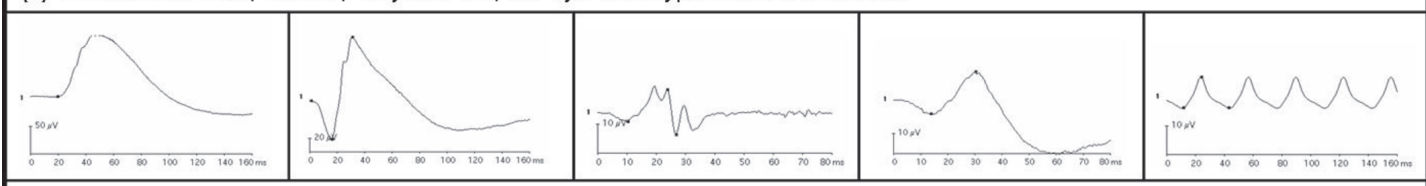

(e) Mixed breed, female, 12 years old, right eye with hypermature cataracts

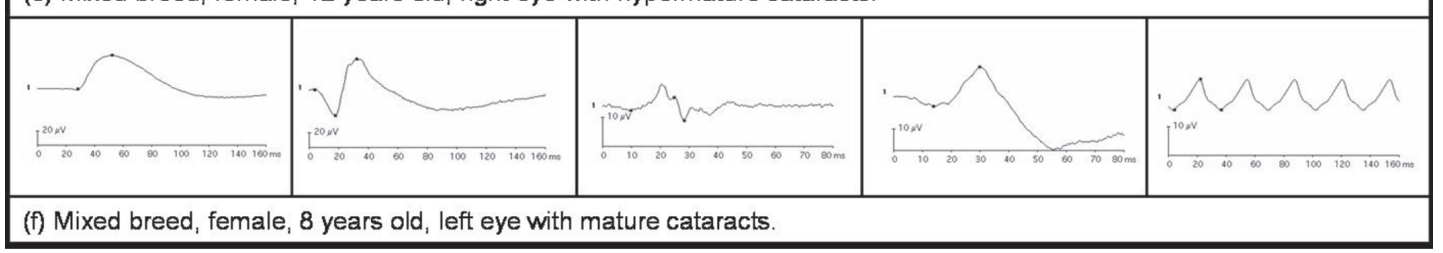

Fig.2. ERG waveforms obtained from three diabetic dogs (d);(e);(f) with mature or hypermature cataracts according to ISCEV protocol.

Table 1. Standard full-field ERG mean peak-topeak amplitudes and b-wave implicit times from the 2 groups (66 dogs)

\begin{tabular}{lcc}
\hline & \multicolumn{2}{c}{ Mean (standard deviation) } \\
\cline { 2 - 3 } & CG (29 dogs) & DG (37 dogs) \\
\hline Age (years) & $10.0(2.6)$ & $10.2(1.8)$ \\
Amplitude (iV) & & \\
Rod response & $52.4(24.8)$ & $50.5(20.5)$ \\
Maximal response & $73.6(35.5)$ & $72.5(29.0)$ \\
Oscillatory potential & $7.9(4.4)$ & $7.4(3.7)$ \\
Cone response & $15.1(9.3)$ & $14.1(7.2)$ \\
Flicker response & $8.2(3.9)$ & $7.2(5.0)$ \\
Implicit time (ms) & & \\
Rod response & $54.5(7.0)$ & $56.5(6.6)$ \\
Maximal response & $31.0(2.7)$ & $31.9(2.0)$ \\
Cone response & $29.8(1.5)$ & $30.7(3.7)$ \\
Flicker response & $22.4(1.4)$ & $24.0(3.8)$
\end{tabular}

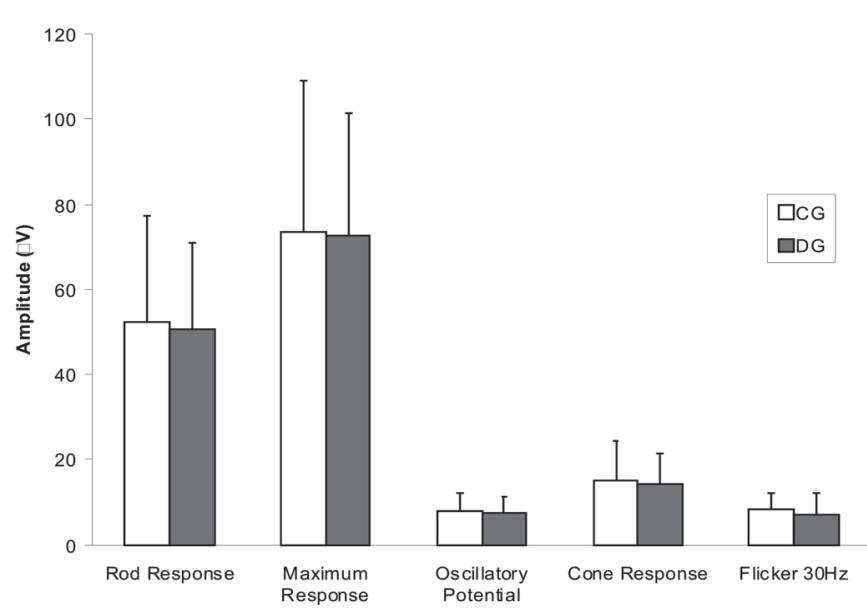

Fig.3. Mean peak-to-peak amplitudes and respective standard deviations for rod, maximal, cone, $30 \mathrm{~Hz}$ flicker responses (average of sinusoidal peak-to-peak responses) and oscillatory potentials from the 2 groups. $\mathrm{m}-=P<0.05$ vs CG.

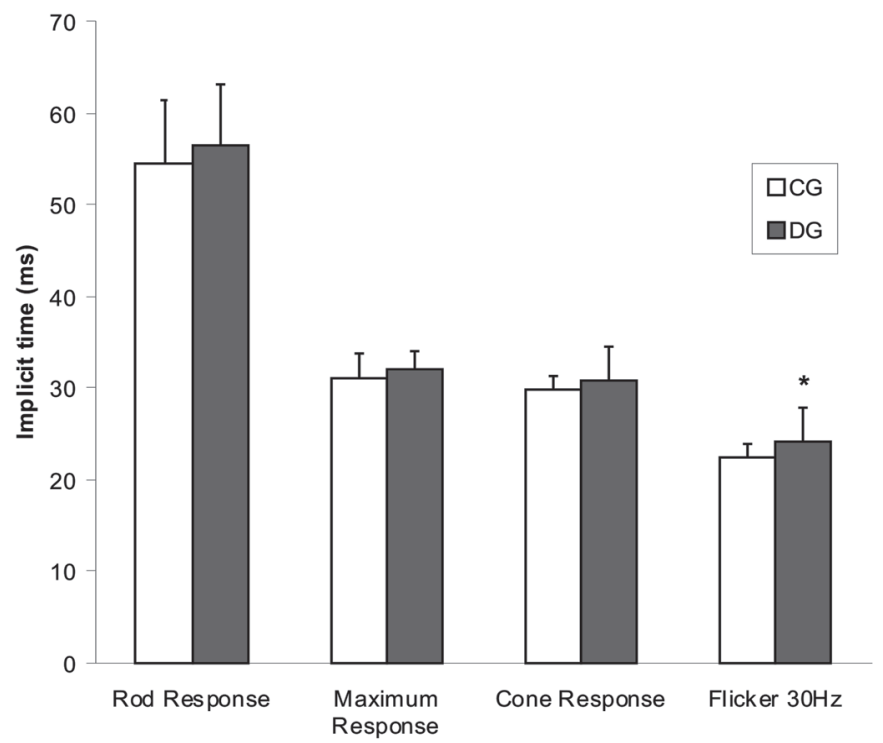

Fig.4. Mean b-wave implicit times and respective standard deviations for rod, maximal, cone and $30 \mathrm{~Hz}$ flicker responses obtained from the 2 groups. $\mathrm{m}-=P<0.05$ vs CG.

and oscillatory potentials obtained from the two groups. These results are plotted, respectively, in Figure 3 and 4.

\section{DISCUSSION}

Being the commonest ocular disorder, dense cataracts disable fundoscopic examination and the diagnosis of retinal disorders, which dogs may be predisposed. Full-field ERG, one of the most required exams before cataract extraction, should be required for being capable to detect retinal function abnormalities in diabetic dogs, which could contra-indicate surgery.

ERG recordings are influenced by many factors, such as pupil size, dark adaptation time, electrodes, stimulus intensity, age, breed (Hérbert et al. 1996, Marmor et al. 
2004, Nusinowitz \& Heckenlively 2006, Petersen-Jones et al. 2006, Ekesten 2007) or intraocular diseases, such as cataracts, lens-induced uveitis (Maehara et al. 2007), glaucoma (Ofri et al. 1993) retinal hereditary degenerations (Safatle et al. 2005) or diabetic retinopathy (Bresnick \& Palta 1987, Layton et al. 2007). In this survey, studied animals did not present any other systemic or ophthalmic disorder then diabetes and mature or hypermature cataracts; each subject was submitted to the same protocol, including dark adaptation time, electrodes, ERG machine, stimulus intensity, sedation protocol and fully pupil dilatation.

Dogs ages from both groups were very similar (medium age: 10.0 yo at $C G$ and 10.2 yo at $D G$ ). Despite each group have presented different breeds, most common studied breeds were Miniature Poodle ( 14 at CG and 5 at DG) and Mixed Breed dogs (7 at CG and 16 at DG). Labrador Retrievers, Schnauzer Terriers and Pugs were referred as predisposed breeds to develop diabetic cataracts (Landry et al. 2004). Other breeds, such as brachycephalic dogs and Shar Pei may also be predisposed to this disorder, because of their difficulty to maintain glucose levels during insulin therapy (Bean et al. 1999). Studied Labrador Retriever and the Schnauzer Terrier were diabetic dogs, but different from other studies just one brachycephalic dog (Lhasa Apso) was observed.

Female dogs were present in a 4:1 proportion to male dogs. Recent studies have shown a decrease in this proportion during the last 20 years (Davidson et al. 2005) what was not observed in this assay.

Cataracts act as a filter that reduces stimulus strength. Therefore, both groups presented cataracts in advanced stage (mature or hypermature). ERG values can also be influenced by lens induced uveitis (LIU) (Maehara et al. 2007), as so, any of the studied dogs presented ophthalmologic alterations, such as red eyes, miosis, low intraocular pressure or other abnormality observed during ocular ultrasound examination that could justify altered values.

Dogs are predisposed to retinal degenerations. Breeds like Miniature Poodle usually present its disease around 5 yo. Studied animals presented medium age of 10.0 yo and alterated ERG recordings that could suggest such degenerations were excluded from the study (Narfström \& Petersen-Jones 2007).

Amplitude reductions and timing delays of various components of the electroretinogram have been reported frequently in diabetic persons presenting diabetic retinopathy (DR) and could be related both to retinopathy severity and to the rate of retinopathy progression. On its early stages, timing delays may be more expected than amplitude reduction in human DR, because timing delays precede amplitude reduction, what was already confirmed at maximal and flicker responses (Bresnick \& Palta 1987). These timing delays in the retina could be compared with the conduction delays described elsewhere in the nervous system in diabetes. Several studies have described conduction delays in others electrophysiological tests in
DM patients, such as prolonged peripheral nerve conduction velocities and visual evoked cortical potential latencies (Puvanendran et al. 1983, Parisi et al. 1997). This study showed similar results, once amplitude reduction and timing delays of all components of the ERG were observed and flicker's timing delays were statistically significant.

Amplitude of oscillatory potentials was found lower in DG when compared to $C G$, but this alteration was not statistically significant. A reduction in this specific response may indicate retinal ischemia, suggesting the DR diagnose in human patients (Tzecov \& Arden 1999). Oscillatory potentials can also be useful for predicting DR progression and be well correlated with its severity (Tzecov \& Arden 1999, Layton et al. 2007). These changes were present in $56.75 \%$ ( 21 of 37 dogs presented values above mean values) of the diabetic dogs.

DR (spontaneous and experimental) was already diagnosed in diabetic dogs, and may be observed by fundoscopic examination as microaneurysms, retinal hemorrhages, tortuous and dilated retinal vessels, hyperreflectivity of tapetal area, and chorioretinal exudates, similarly with the beginning of the human diabetic retinopathy (Muñana 1995). Otherwise, retinal abnormalities in dogs are generally impossible to observe by fundoscopic examination because of cataracts, making necessary the utilization of other exams such as full-field ERG and ocular ultrasonography.

Besides DR, retinal bleeding can also be induced by systemic arterial hypertension, immune mediated diseases, thrombocytopenia, coagulopathies, infection and hyper viscosity syndrome, leading to rapid retinal lesions (Cullen $\&$ Webb 2007). None of the studied dogs presented any systemic disease that could justify alterations on ERG responses.

In dogs with spontaneous diabetes, DR takes approximately 3 to 5 years to develop, whereas in dogs with experimental diabetes it might take almost 2 years (Cullen \& Webb 2007). In this study, just 3 dogs had diabetes for more than 3 years and 9 had the disease for at least 1 year. Either way, ERG changes could be detected by this exam. Similar observation was already found in ERGs recorded from children with insulin-dependent diabetes mellitus that did not present any fundoscopic or fluorescein angiography alteration that could confirm DR at the time that ERG was recorded, but developed the disease some time later, suggesting that ERG is capable to detect early DR alterations, even before the appearance of other symptoms (Tzecov \& Arden 1999).

Authors suggests that more studies should be performed to diagnose DR in dogs after ERG examination, such as fundoscopic examination after cataracts removal or retinal histopathology, where thickening of basement membrane in retinal capillaries, dilation of retinal veins, loss of pericytes, microaneurysms, and areas of capillary no perfusion may be observed (Landry et al. 2004).

In conclusion, full-field ERGs were successfully obtained from non diabetic and diabetic dogs, both presenting mature 
or hypermature cataracts. Flicker timing was statistically altered in diabetic dogs, suggesting that this alteration may predict nerve conduction delays, what may be seen at retinal vascular abnormalities.

Acknowledgements.- This study was supported by the Fundação de Amparo à Pesquisa do Estado de São Paulo (FAPESP, Grant no.02/ 08051-9).

\section{REFERENCES}

Beam S., Correa M.T. \& Davidson M.G. 1999. A Retrospective-cohort study on the development of cataracts in dogs with diabetes mellitus: 200 cases. Vet Ophthalmol. 2:169-172.

Bresnick G.H. \& Palta M. 1987. Temporal aspects of the electroretinogram in diabetic retinopathy. Arch Ophthalmol. 105:660-664.

Cullen C.H. \& Webb A. 2007. Ocular manifestations of systemic disease part 1: the dog, p.1470-1537. In: Gelatt K.N. (Ed.), Veterinary Ophthalmology. $4^{\text {th }}$ ed. Blackwell Publishing, lowa.

Davison L.J., Herrtage M.E. \& Catchpole B. 2005. Study of 253 dogs in the United Kingdom with diabetes mellitus. Vet Rec. 9:467-471.

Ekesten B. 2007. Ophthalmic examination and diagnostics, p.520-535. In: Gelatt K.N. (Ed.), Veterinary Ophthalmology. $4^{\text {th }}$ ed. Blackwell Publishing, lowa

Hendrix D.V.H. \& Sims M.H. 2004. Electroretinography in Hispaniolan Amazon Parrot (Amazona ventralis). J. Avian Med. Surg. 18:89-94.

Hérbert M., Lachapelle P. \& Dumont M. 1996. Reproducibility of electroretinograms recorded with DTL electrodes. Doc. Ophthalmol. 91:333-342.

Hurn S.D., Hardman C. \& Stanley R.G. 2003. Day-blindness in three dogs: clinical and electroretinographic findings. Vet. Ophthalmol. 6:127-130.

Kim S.H., Lee S.G., Bae J.Y., Cho J.H. \& Kang Y.S. 1998. Electroretinographic evaluation in adult diabetics. Doc. Ophthalmol. 94:201213.

Komaromy A.M., Smith P.J. \& Brooks D.E. 1998. Electroretinography in dogs and cats. Part I. Retinal morphology and physiology. Compend. Contin. Educ. 20:343-354.

Komaromy A.M., Andrew S.T., Sapp Jr. H.L., Brooks D.E. \& Dawson W.W. 2003. Flash electroretinography in standing horses using the DTL ${ }^{\mathrm{tm}}$ microfiber electrode. Vet. Ophthalmol. 6:27-33.

Landry M.P., Herring I.P. \& Panciera D.L. 2004. Fundoscopic findings following cataract extraction by means of phacoemulsification in diabetic dogs: 52 cases (1993-2003). J. Am. Vet. Med. Assoc. 225:709-716.

Layton C.J., Safa R. \& Osborne N.N. 2007. Oscillatory potentials and the b-wave: partial masking and interdependence in dark adaptation and diabetes in the rat. Graefe's Arch. Clin. Exp. Ophthalmol. 245:1335-1345.

Maehara S., Itoh N., Wakaiki S., Tsuzuki K., Seno T., Kushiro T., Yamashita K., Izumisawa Y. \& Kotani T. 2005. Electroretinography using contact lens electrode with built-In light source in dogs. J. Vet. Med. Sci. 67:509-514.

Maehara S., Itoh N., Wakaiki S., Yamasaki A., Tsuzuki K. \& Izumisawa Y. 2007. The effects of cataract stage, lens-induced uveitis and cataract removal on ERG in dogs with cataract. Vet. Ophthalmol. 10:308-312.

Marmor M.F., Holder G.E., Seeliger N.W. \& Yamamoto S. 2004. Standard for clinical electroretinography (2004 update). Doc. Ophthalmol. 108:107-114.

Muñana, K.R. 1995. Long-term complications of diabetes mellitus, part I: retinopathy, nephropathy, neuropathy. Vet. Clin. North Am. 25:715730.

Narfström K., Ekesten B., Rosolen S.G., Spiess B.M., Percicot C.L. \& Ofri R. 2002. Guidelines for clinical electroretinography in the dog. Doc. Ophthalmol. 105:83-92.

Narfström K. 2006. Electroretinographic testing in larger animals, p.923933. In: Heckenlively J.R. \& Arden G.B. (Eds), Principles and Practice of Clinical Electrophysiology of Vision. The Mit Press, Cambridge.

Narfström K. \& Petersen-Jones S. 2007. Disease of the canine ocular fundus, p.994-1025. In: Gelatt K.N. (Ed.), Veterinary Ophthalmology. $4^{\text {th }}$ ed. Blackwell Publishing, lowa.

Nusinowitz S. \& Heckenlively J.R. 2006. Evaluating retinal function in the mouse retina with the electroretinogram, p.899-909. In: Heckenlively J.R. \& Arden G.B. (Eds), Principles and Practice of Clinical Electrophysiology of Vision. The Mit Press, Cambridge.

Ofri R., Dawson W.W., Foli K. \& Gelatt K.N. 1993. Chronic ocular hypertension alters local retinal responsiveness. Brit. J. Ophthalmol. 77:502-508.

Ofri R. 2008. Lens p.258-276. In: Maggs D.J., Miller P.E. \& Ofri R. (Eds), Slatter's Fundamentals of Veterinary Ophthalmology. $4^{\text {th }}$ ed. Saunders Elsevier, Philadelphia.

Parisi V., Uccioli L., Monticone G., Parisi L., Manni G., Ippoliti D., Menzinger G. \& Bucci M.G. 1997. Electrophysiological assessment of visual function in IDDM patients. Electroencephalogr. Clin. Neurophysiol. 104:171-179.

Petersen-Jones S., Tuntivanich N. \& Montiani-Ferreira F. 2006. Electroretinograms of dog and chicken, p.911-921. In: Heckenlively J.R. \& Arden G.B. (Eds), Principles and Practice of Clinical Electrophysiology of Vision. The Mit Press, Cambridge.

Puvanendran K., Devathasan G. \& Wong P.K. 1983. Visual evoked responses in diabetes. J. Neurol. Neurosurg. Psychiatry 46:643647.

Rand J.S., Fleeman L.M., Farrow H.A., Appleton D.J. \& Lederer R. 2004. Canine and feline diabetes mellitus: Nature or nurture? J. Nutr. 13(Suppl.):2072-2080.

Rubin L.F. 1971 Clinical features of hemeralopia in adult Alaskan Malamute. J. Am. Vet. Med. Assoc. 158:1696-1698.

Safatle A.M.V., Salomão S., Berezovsky A., Sacai P., Fantoni D., Yazbek K. \& Barros P.S.M. 2005. Retinal degeneration in a Pit Bull dog: Electroretinographic findings. Arch. Vet. Sci. 10:119-124.

Tzecov R. \& Arden G.B. 1999. The electroretinogram in diabetic retinopathy. Surv. Ophthalmol. 44: 53-60.

Wilkie D.A., Gemensky-Metzler A.J., Colitz C.M.H., Bras I.D., Kuonen V.J., Norris K.N. \& Basham C.R. 2006. Canine cataracts, diabetes mellitus and spontaneous lens capsule rupture: A retrospective study of 18 dogs. Vet. Ophthalmol. 9(5):328-334.

Wilkie D.A. \& Colitz C.M.H. 2007. Surgery of the canine lens, p.888931. In: Gelatt K.N. (Ed.), Veterinary Ophthalmology. $4^{\text {th }}$ ed. Blackwell Publishing, lowa. 